\title{
B7-H3 combats apoptosis induced by chemotherapy by delivering signals to pancreatic cancer cells
}

\author{
Dongbao Li ${ }^{1,2,3,4,5, *}$, Jun Wang ${ }^{6, *}$, Jian Zhou ${ }^{1,2, *}$, Shenghua Zhan ${ }^{7}$, Yang Huang ${ }^{1,2,4,5}$, \\ Fei Wang ${ }^{1}$, Zixiang Zhang ${ }^{1,2}$, Dongming Zhu ${ }^{1,2}$, Hua Zhao ${ }^{1}$, Dechun Li ${ }^{1,2}$, Gang \\ Chen $^{8}$, Xinguo Zhu ${ }^{1}$ and Xin Zhao ${ }^{1,2,4,5}$ \\ ${ }^{1}$ Department of General Surgery, The First Affiliated Hospital of Soochow University, Suzhou, China \\ ${ }^{2}$ Pancreatic Disease Research Center, The First Affiliated Hospital of Soochow University, Suzhou, China \\ ${ }^{3}$ Department of HBP, Suzhou Dushuhu Public Hospital, Soochow University Multi-Disciplinary Polyclinic, Suzhou, China \\ ${ }^{4}$ Jiangsu Key Laboratory of Clinical Immunology, Soochow University, Suzhou, China \\ ${ }^{5}$ Jiangsu Key Laboratory of Gastrointestinal Tumor Immunology, The First Affiliated Hospital of Soochow University, Suzhou, \\ China \\ ${ }^{6}$ Department of Emergency, The First Affiliated Hospital of Soochow University, Suzhou, China \\ ${ }^{7}$ Department of Pathology, The First Affiliated Hospital of Soochow University, Suzhou, China \\ ${ }^{8}$ Department of Hepatobiliary Surgery, The First Affiliated Hospital, Wenzhou Medical University, Wenzhou, China \\ *These authors have contributed equally to this work \\ Correspondence to: Xin Zhao, email: zhaox@suda.edu.cn
}

Xinguo Zhu, email: zxg45@hotmail.com

Gang Chen, email: chen.gang@wmu.edu.cn

Keywords: chemotherapy resistance, gemcitabine, Panc-1, pancreatic cancer, patu8988

Received: April 13,2017 Accepted: June 18, $2017 \quad$ Published: August 24, 2017

Copyright: Li et al. This is an open-access article distributed under the terms of the Creative Commons Attribution License 3.0 (CC BY 3.0), which permits unrestricted use, distribution, and reproduction in any medium, provided the original author and source are credited.

\section{ABSTRACT}

Objective: This study aimed to investigate the role of B7-H3 in chemotherapy resistance of pancreatic cancer cells and discover the potential signal transduction pathway and molecular targets involved.

Methods: Immunohistochemical staining and real-time polymerase chain reaction (PCR) were used to determine the expression of B7-H3 in clinical specimens. Clinical data were applied to survival analysis. Phosphoprotein was purified from cultured Patu8988 cells using the Phosphoprotein Purification Kit. Cell apoptosis was detected using propidium iodide-Annexin $\mathrm{V}$ staining to investigate the relation between the expression of B7-H3 and Patu8988 cells treated with gemcitabine. Western blot was used to determine the effect of $\mathrm{B} 7-\mathrm{H} 3$ on the expression of proteins including extracellular signal-regulated kinase (ERK)1/2, epidermal growth factor receptor (EGFR), and Inhibitor of NF-KB(IKB) in Patu8988 cells; B7-H3 was activated by 4H7, which as an agonist monoclonal antibody to B7-H3.

Results: The expression of $\mathrm{B} 7-\mathrm{H} 3$ was found to be higher in tumor tissues than in normal tissues of pancreatic carcinoma. Survival analysis revealed that patients in the low-B7-H3 expression group were likely to have a longer overall survival compared with those in the high-expression group $(P<0.05)$. B7-H3 activated by $4 \mathrm{H7}$ could reduce gemcitabine-induced apoptosis in Patu8988 cells. Activation of B7H3 by $4 \mathrm{H7}$ induced variations in p-ERK1/2, EGFR, and IKB protein levels. When B7-H3 was upregulated, the expression levels of EGFR and p-ERK1/2 proteins significantly 


\section{increased $(P<0.05)$, but the expression level of IKB significantly decreased $(P<$ $0.05)$, especially in the gemcitabine-treated group. \\ Conclusion: This study demonstrated that B7-H3 could deliver signals to pancreatic cancer cells to combat apoptosis induced by gemcitabine.}

\section{INTRODUCTION}

Recent advances in pancreatic surgery have the potential to improve outcomes for patients with pancreatic cancer [1]. However, the 5-year survival rate is only about $6 \%[2]$. Moreover, this highly aggressive cancer is resistant to chemotherapy and radiation therapy [3]. Gemcitabine, the standard chemotherapy drug for advanced pancreatic cancer, has shown limited benefits because of profound chemoresistance [4]. As a first-line chemotherapeutic drug for pancreatic cancer, gemcitabine showed efficacy in less than $20 \%$ of treated patients [5]. Zhang et al [6] demonstrated a novel mechanism underlying acquired gemcitabine resistance in pancreatic cancer cells by inducing stemness via a Nox/ROS/NF- $\mathrm{kB} / \mathrm{STAT3}$ signaling pathway. Zhao et al [7] found that $\mathrm{B} 7-\mathrm{H} 3$ induced gemcitabine resistance in pancreatic carcinoma cells, at least partially, by downregulating survivin expression. However, the mechanism involved remains unclear. Therefore, it is urgent to elucidate the mechanisms by which chemoresistance occurs in patients with pancreatic cancer to achieve better therapeutic efficacy.

B7-H3, a novel member of the B7 family of costimulatory proteins, consists of two isoforms $2 \mathrm{IgB} 7 \mathrm{H} 3$ and $4 \operatorname{IgB} 7 \mathrm{H} 3$ [8]. The latter is more widely expressed in mature dendritic cells, $T$ cells, and many human tumor cell lines including pancreatic cancer [9-11]. Zhang et al [12] declared that $\mathrm{B} 7-\mathrm{H} 3$ might promote $\mathrm{U} 937$ cell progression, and short hairpin RNA (shRNA) targeting B7-H3 significantly enhanced sensitivity to chemotherapeutic drugs. Zhang et al [13] showed that the overexpression of B7-H3 augmented anti-apoptosis of colorectal cancer cells by JAK2-STAT3. Many studies demonstrated that B7H3 was closely correlated with chemotherapy resistance and apoptosis of pancreatic cancer cells. However, the mechanism of abnormal expression of $\mathrm{B} 7-\mathrm{H} 3$ in pancreatic cancer and its role in the changes in tumor biological behavior need to be further determined. Therefore, this study focused on the role of B7-H3 in chemotherapy resistance in pancreatic cancer cells to elucidate the signal transduction pathway and potential molecular targets involved.

\section{RESULTS}

\section{Expression of $\mathrm{B} 7-\mathrm{H3}$ was higher in tumor tissue than in a normal tissue of pancreatic carcinoma}

The immunohistochemical staining method was used to detect the expression of B7-H3 in clinical surgical specimens of 42 patients with pancreatic carcinoma.
The results revealed that B7-H3 was significantly overexpressed in the tumor tissue. Also, 19 tumor specimens showed high expression of B7-H3 (45.24\%), 6 showed low expression of B7-H3 (14.29\%), and 17 showed no expression (40.48\%) (Figure 1). Moreover, real-time PCR determined the relative mRNA expression levels of B7-H3 in pancreatic carcinoma tissues and adjacent normal pancreatic tissues of the patients. The result showed that the relative mRNA expression levels of B7-H3 were markedly higher in pancreatic carcinoma tissues than in adjacent normal pancreatic tissues $(P<$ 0.001) (Figure 2).

\section{Survival analysis}

The survival curve is presented in Figure 3. Thirtyfive deaths occurred. The cumulative median survival in patients with high and low expression of $\mathrm{B} 7-\mathrm{H} 3$ after the surgery was 10 and 18 months, respectively. Patients in the low-expression group were likely to have a longer overall survival compared with those in the high-expression group $(P<0.05)$

\section{Identification of phosphorylated $\mathrm{B} 7-\mathrm{H} 3$ protein in Patu8988 cells stimulated with $4 \mathrm{H} 7$}

The Qiagen Phosphoprotein Purification Kit was used to isolate phosphorylated proteins from the Patu8988 cell lysate. The cell lysate (Lfraction) was loaded on a column containing aphosphoprotein-binding resin, and the phosphorylated proteins were subsequently eluted (E fraction). Then, phosphorylated B7-H3 and entire B7H3 were detected by Western blot with the anti-human B7-H3 antibody. The results revealed that B7-H3 was phosphorylated after stimulation with $4 \mathrm{H} 7(* * * P<0.001)$ (Figure 4A and 4B), indicating signal conduction in the cells.

\section{Activation of $\mathrm{B} 7-\mathrm{H3}$ reduced gemcitabine- induced apoptosis in Patu8988 cells}

Gemcitabine exerts its cytotoxic effect by inducing tumor cell apoptosis. B7-H3 antibody $4 \mathrm{H} 7$ was developed in a previous study. Therefore, this study investigated the correlation between gemcitabine cytotoxicity observed in Patu8988 cells, in which B7-H3 was activated by $4 \mathrm{H} 7$ for $48 \mathrm{~h}$, and its effects on apoptosis. After different treatments for $48 \mathrm{~h}$, the early and late apoptosis of Patu8988 cells were measured separately using PI-Annexin V staining. The dot plots of Patu8988 cell apoptosis shown in Figure 5 exhibit that early apoptosis increased when the dose of 


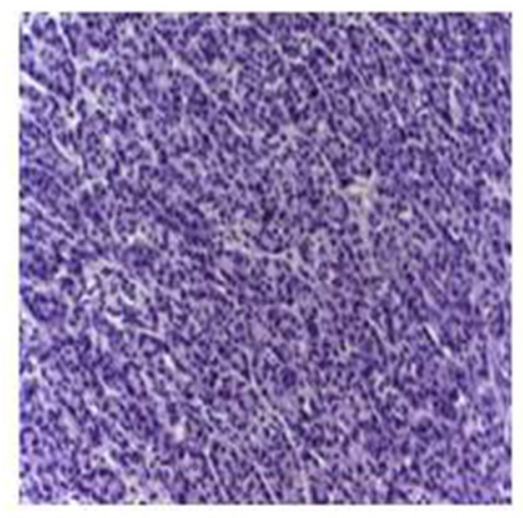

\section{A1. Normal Pancreas}



B1. Pancreatic cancer

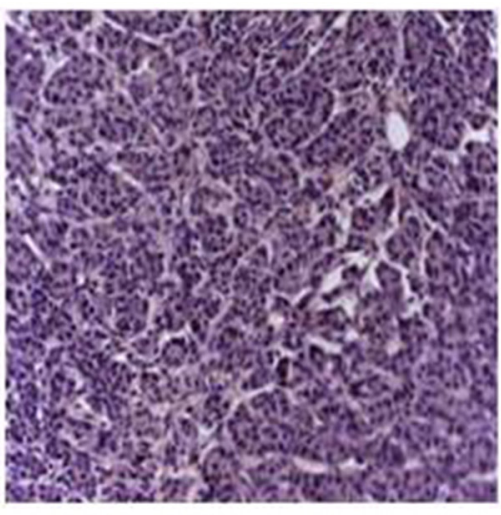

A2. Normal Pancreas

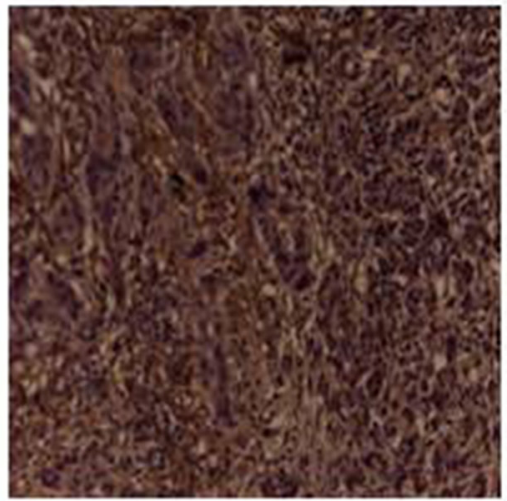

B2. Pancreatic cancer

Figure 1: Immunohistochemical staining for B7-H3 in clinical specimens. (A1) No expression in normal pancreas. (A2) Low expression in normal pancreas. (B1) Low expression in pancreatic cancer tissue. (B2) Overexpression in pancreatic cancer tissue (magnification, 200×).

\section{B7-H3/GAPDH}

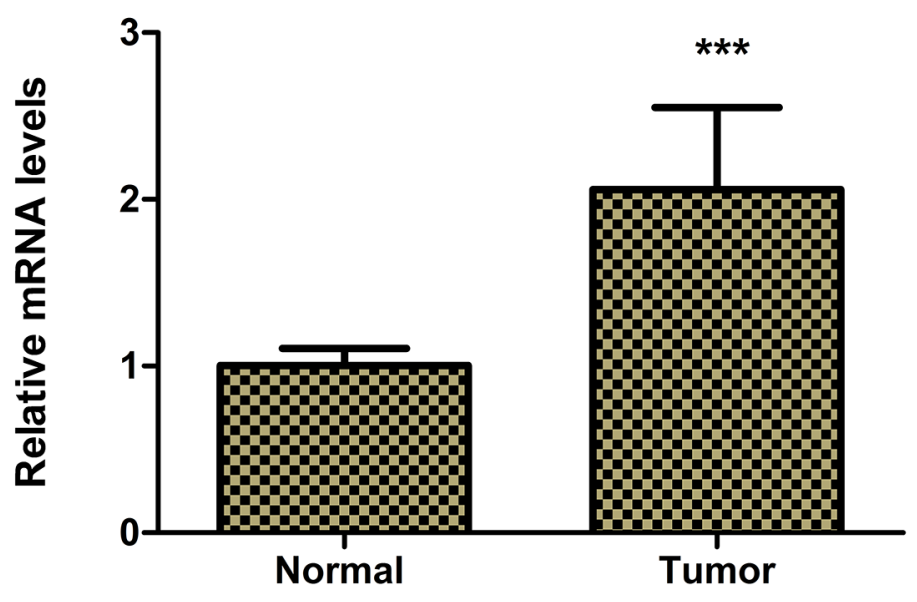

Figure 2: Real-time PCR determined the relative mRNA expression levels of B7-H3 in pancreatic carcinoma tissues and adjacent normal pancreatic tissues of $\mathbf{4 2}$ patients with pancreatic carcinoma. The relative mRNA expression levels of B7-H3 were markedly higher in pancreatic carcinoma tissues than in adjacent normal pancreatic tissues $(* * * P<0.001)$. 
gemcitabine was improved, whereas it decreased after B7H3 was activated by $4 \mathrm{H} 7(P<0.05)$. Hence, it could be concluded that activation of $\mathrm{B} 7-\mathrm{H} 3$ reduced gemcitabineinduced early apoptosis in Patu8988 cells.

\section{Activation of $\mathrm{B} 7-\mathrm{H3}$ by $4 \mathrm{H} 7$ induced variations in p-ERK1/2, EGFR, and IKB protein levels}

The activation of B7-H3 can reduce gemcitabineinduced early apoptosis in Patu8988 cells. Hence, Western blot was used to determine the effect of B7-H3 on the expression of apoptosis proteins in Patu8988 cells. The cells were treated with $4 \mathrm{H} 7$ (1 and $5 \mathrm{ng} / \mathrm{mL}$ ) for $24 \mathrm{~h}$. The results showed that treatment with $4 \mathrm{H} 7$ led to variations in p-ERK1/2, EGFR, and I $\mathrm{B}$ protein levels (Figure 6A). The expression of $\mathrm{p}-\mathrm{ERK} 1 / 2$ and EGFR was upregulated in a dose-dependent manner, whereas the expression of $\mathrm{I} \kappa \mathrm{B}$ was downregulated (Figure $6 \mathrm{~B}$ ). This indicated that activation of $\mathrm{B} 7-\mathrm{H} 3$ by $4 \mathrm{H} 7$ induced variations in the levels of downstream molecules of ERK1/2, EGFR, and $\mathrm{I} \kappa \mathrm{B}$, which might be associated with pancreatic cancer resistance to gemcitabine chemotherapy.

\section{Transfection efficiency of the lentivirus gene transfer vectors}

Patu8988 and Panc-1 cells were observed under a fluorescence microscope $72 \mathrm{~h}$ after transfection with lentivirus gene transfer vectors (Figure 7A and 7B) and examined by FCM (Figure 7C). Infected positive cell ratio of $\mathrm{LV}-\mathrm{B} 7-\mathrm{H} 3^{+} /$ Panc-1 and $\mathrm{LV}-\mathrm{NC}^{+}$Panc-1 cells was $95.0 \%$ and $99.2 \%$, respectively. The result showed high efficiency of transfection.

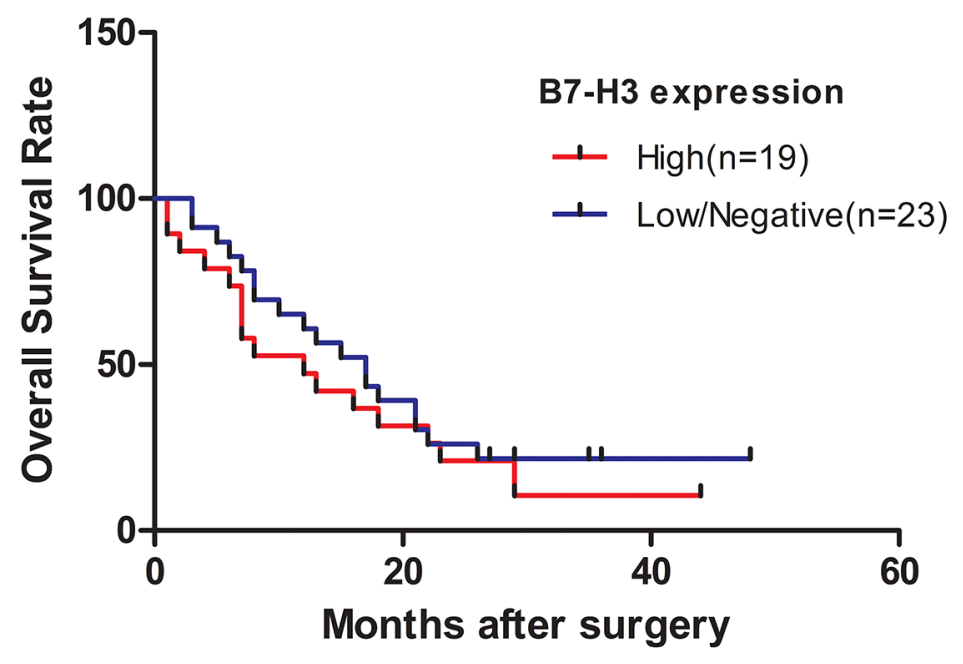

Figure 3: Survival curve of patients with pancreatic cancer stratified according to the expression levels of B7-H3. Patients in the low-expression group were likely to have a longer overall survival compared with those in the high-expression group $(P<0.05)$.

A.



B.



Figure 4: Phosphorylated B7-H3 protein was detected in the phosphoprotein fraction purified using a Qiagen Phosphoprotein Purification Kit in the Patu8988 cell line. (A) The cells were divided into 4H7-stimulated group and control group. First, phosphorylated proteins were extracted from each group. Then, phosphorylated B7-H3 and entire B7-H3 were detected by Western blot. The results revealed that B7-H3 was phosphorylated after stimulation by 4H7. (B) The relative protein expression levels of phosphorylated $\mathrm{B} 7-\mathrm{H} 3$ were markedly high after stimulation by $4 \mathrm{H} 7(* * * \mathrm{P}<0.001)$. 


\section{Expression of EGFR was positively associated with the expression of $\mathrm{B} 7-\mathrm{H} 3$ after cells were treated with gemcitabine}

RT-PCR was performed to demonstrate the relative mRNA expression of B7-H3 and EGFR in Panc-1/NC, Panc1/B7-H3 ${ }^{+}$, Patu8988/NC, and Patu8988/B7-H3- cell lines to investigate the relationship between B7-H3 and apoptosis in PC cell lines. The aforementioned cell lines were treated with gemcitabine ( $4 \mathrm{mmol} / \mathrm{mL}, 48 \mathrm{~h}$ ). Both B7-H3 overexpression in Panc-1 cells and downregulation in Patu8988 cells affected the relative mRNA expression of EGFR (Figure 8A and 8B). The expression of B7-H3 increased in Panc-1/B7-H3 ${ }^{+}$cells compared with Panc-1/NC cells $(P<0.05)$, and the relative mRNA expression of EGFR also increased $(P<0.05)$. The expression of B7-H3 decreased in Patu8988/B7-H3- cells compared with Patu8988/NC cells $(P<0.05)$, and the relative mRNA expression of EGFR also decreased $(P<0.05)$. Based
A.



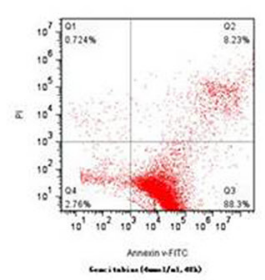

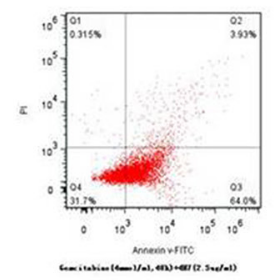

B.

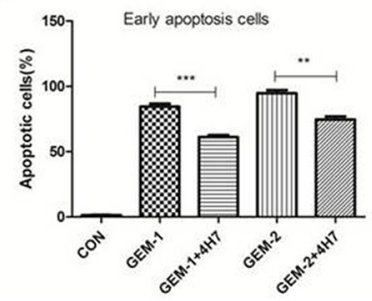

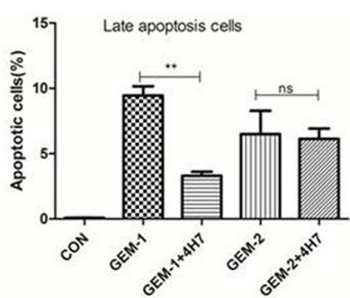
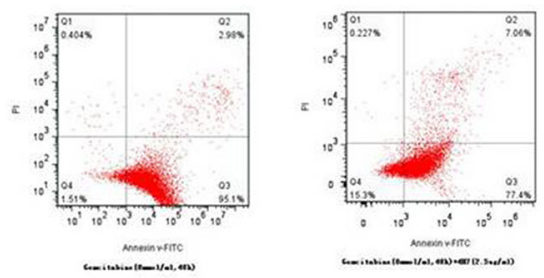

Figure 5: Flow cytometric analysis of Annexin V-FITC/PI to quantify gemcitabine-induced apoptosis in Patu8988 cells. (A) The dot plots of Patu8988 cells treated with 4 and $8 \mathrm{mmol} / \mathrm{mL}$ of gemcitabine or $2.5 \mu \mathrm{g} / \mathrm{mL} 4 \mathrm{H} 7 \mathrm{for} 48 \mathrm{~h}$ are shown. (B) The early apoptosis increased when the dose of gemcitabine was improved, whereas it decreased after B7-H3 was activated by $4 \mathrm{H} 7$ (P $<0.05$ ). This effect was not observed in late apoptosis. The results shown are representative of three independent experiments.

A.

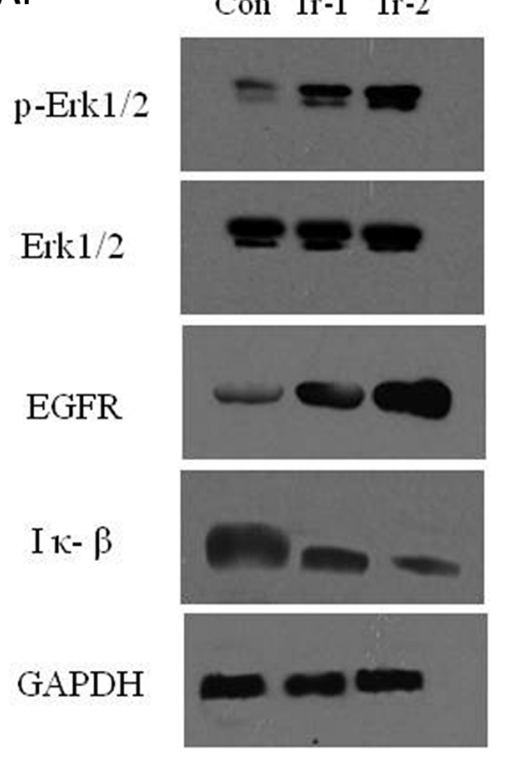

B.

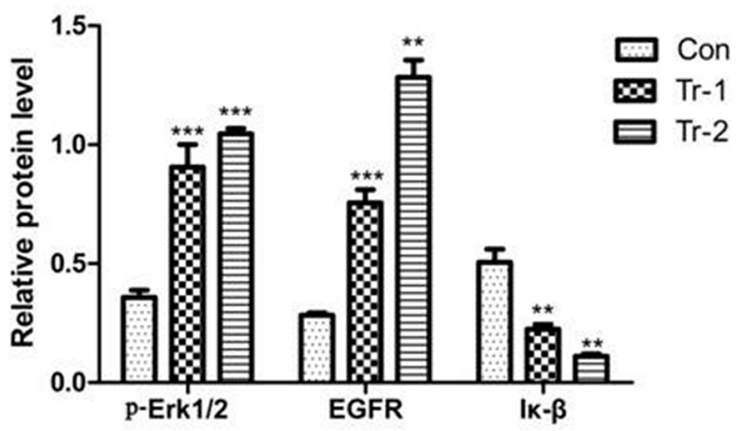

Figure 6: WT/Patu8988 cells were treated with different concentrations of $4 \mathrm{H} 7$ for $24 \mathrm{~h}$. (A) Western Blot was used to determine p-Erk1/2, Erk1/2, EGFR, and IkB protein levels. (B) The relative protein expression levels as determined by densitometric analysis of the Western blot results. Results are presented as mean \pm standard deviation. The expression of p-Erk1/2 and EGFR was upregulated in a dose-dependent manner, whereas the expression of IкB was downregulated (con, control; Tr-1, $1 \mathrm{ng} / \mathrm{mL} 4 \mathrm{H} 7$; $\operatorname{Tr}-2,5 \mathrm{ng} /$ $\mathrm{mL} 4 \mathrm{H} 7)(* * * \mathrm{P}<0.001 ; * * \mathrm{P}<0.01)$. 
on the data in this figure, that B7-H3 expression levels are positively associated with EGFR levels.

\section{Upregulation of B7-H3 slacked gemcitabine- induced apoptosis in Panc-1 cells}

A previous study showed that silencing of the expression of B7-H3 by shB7-H3 made the Patu8988 cells more prone to gemcitabine-induced apoptosis [7]. This study found the overexpression of B7-H3 in Panc-1/B7-H3 ${ }^{+}$cells and the control cell line Panc-1/NC, on treatment with gemcitabine (4 $\mathrm{mmol} / \mathrm{mL}, 8 \mathrm{mmol} / \mathrm{mL} ; 48 \mathrm{~h}, 72 \mathrm{~h}$, respectively). Then, the PI-Annexin V Staining Apoptosis Detection Kit I manual was implemented to measure the percentage of PI-stained cells. The results showed that the percentage of PI-stained cells in Panc-1/B7-H3 ${ }^{+}$cells was less than the percentage in Panc-1/ NC cells (Figure 9A and 9B) $(P<0.05)$. Also, the response to gemcitabine was dose- and time-dependent. The figure only shows the result at $72 \mathrm{~h}$. The results demonstrated that the upregulation of B7-H3 slacked gemcitabine-induced apoptosis in Panc-1 cells similar to Patu8988 cells.

\section{B7-H3 accommodated variation in EGFR protein to mediate pancreatic cancer cell resistance to gemcitabine-induced apoptosis}

The expression of EGFR was associated with the expression of $\mathrm{B} 7-\mathrm{H} 3$ in the $\mathrm{PC}$ cells resistant to gemcitabine. The present study aimed to investigate the signaling pathway involved and potential molecular mechanisms. Western blot analysis was conducted to determine the relative protein level. Bcl-2, Bax, Bcl$\mathrm{xL}, \mathrm{EGFR}, \mathrm{ERK} 1 / 2$, and I $\mathrm{B}$ proteins were detected by Western blot and semi-quantitative analysis using the Image J software. Panc-1/WT, Panc-1/NC, Panc-1/B7-H3 ${ }^{+}$, Patu8988/WT, Patu8988/NC, and Patu8988/B7-H3- cell lines were treated with gemcitabine $(8 \mathrm{mmol} / \mathrm{mL}, 48 \mathrm{~h})$, while the control group received no treatment. Wholecell lysates were used for detecting the expression levels of aforementioned proteins. The results revealed that the expression levels of Bcl-2, Bax, and Bcl-xL proteins had no obvious difference in Patu8988/WT, Patu8988/NC, and Patu8988/B7-H3 cell lines, regardless of gemcitabine treatment $(P>0.05)$ (Figure 10A). However, when B7-H3 was downregulated, the expression levels of EGFR and ERK1/2 proteins significantly decreased $(P<0.05)$, and the expression level of I $\kappa \mathrm{B}$ protein significantly increased $(P<$ 0.05 ) (Figure 10A), especially in the gemcitabine-treated group after processing. Similar results were obtained in Panc-1cell lines. The results showed that the expression levels of Bcl-2, Bax, and Bcl-xL proteins had no obvious difference in Panc-1/WT, Panc-1/NC, and Panc-1/B7-H3 ${ }^{+}$ cell lines, regardless of gemcitabine treatment $(P>0.05)$ (Figure 10B). However, when B7-H3 was upregulated, the expression levels of EGFR and ERK1/2 proteins significantly increased $(P<0.05)$, and the expression level of IкB protein significantly decreased $(P<0.05)$ (Figure 10B), especially in the gemcitabine-treated group. These

A.

A.



c.

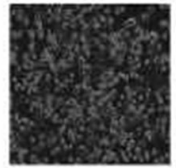

B.


B.



III.



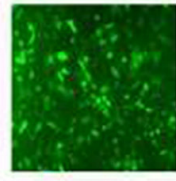

IV.

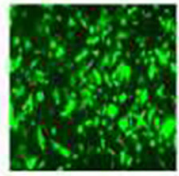

C.
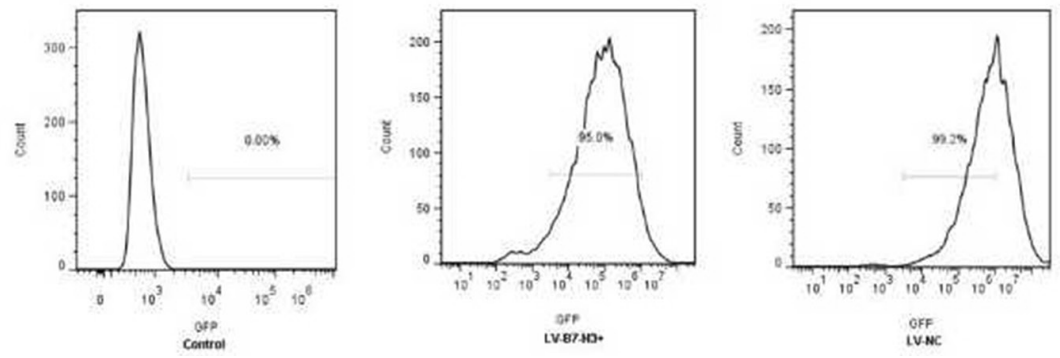

Figure 7: (A) Patu8988 cells displaying bright-field and green fluorescence (original magnification: 100×). (A and B) White light and green fluorescence of shB7-H3/Patu8988 cells. (C and D) White light and green fluorescence of LV-NC//Patu8988 cells. (B) Panc-1 cells displaying bright-field and green fluorescence (original magnification: $100 \times$ ). (I and II) White light and green fluorescence of LV-B7H3 + Panc-1 cells. (III and IV) White light and green fluorescence of LV-NC $/$ Panc-1 cells. (C) Expression of GFP was assessed by FCM. Infected positive cell ratio of LV-B7-H3 ${ }^{+} /$Panc- 1 and LV-NC ${ }^{+} /$Panc- 1 cells was $95.0 \%$ and $99.2 \%$, respectively. 
results indicated that $\mathrm{B} 7-\mathrm{H} 3$ could accommodate variations in EGFR protein to mediate pancreatic cancer cell resistance to gemcitabine-induced apoptosis.

\section{DISCUSSION}

This novel study confirmed that the expression of B7-H3 was higher in tumor tissues than in normal tissues of pancreatic carcinoma. Other studies also showed that the expression of B7-H3 was significantly associated with poor outcome in colon cancer [14]. Wu et al [15] reported that the expression of $\mathrm{B} 7-\mathrm{H} 3$ was related to survival time in gastric cancer cases. Zhao et al [16] discovered that the overexpression of B7-H3 in pancreatic cancer promoted tumor progression. Zhang et al [17] found that circulating B7-H3 was a valuable biomarker for nonsmall cell lung
A.

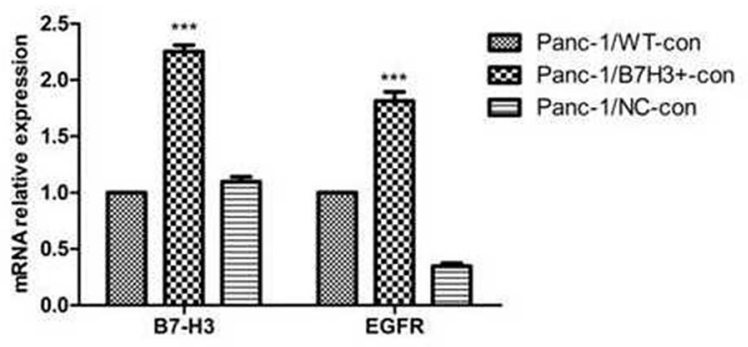

B.



$\approx$ Patu8988/WT-con $\infty$ Patu8988/RNAi-con 四atu8988/NC-con

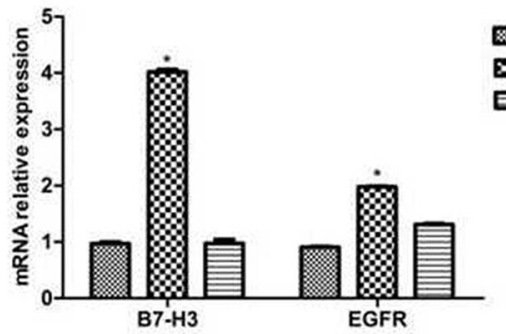

anc-1/WT-Tre

$\infty \times$ Panc-1/B7H3+-Tre

D Panc-1/NC-Tre

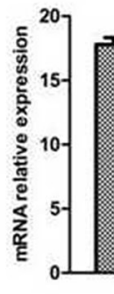

Patu8988/WT-Tre Patu8988/RNAi-Tre 曰 Patu8988/NC-Tre

Figure 8: Relative mRNA expression of B7-H3 and EGFR was analyzed using the $\mathbf{2}^{-\Delta A C t}$ method for different cell lines. (A) Expression of B7-H3 increased in Panc-1/B7-H3+ cells compared with Panc-1/NC cells $(\mathrm{P}<0.05)$, and the relative mRNA expression of EGFR also increased $(\mathrm{P}<0.05)$. (B) Expression of B7-H3 decreased in Patu8988/B7-H3- cells compared with Patu8988/NC cells $(\mathrm{P}<$ $0.05)$, and the relative mRNA expression of EGFR also decreased $(\mathrm{P}<0.05)$.

A.
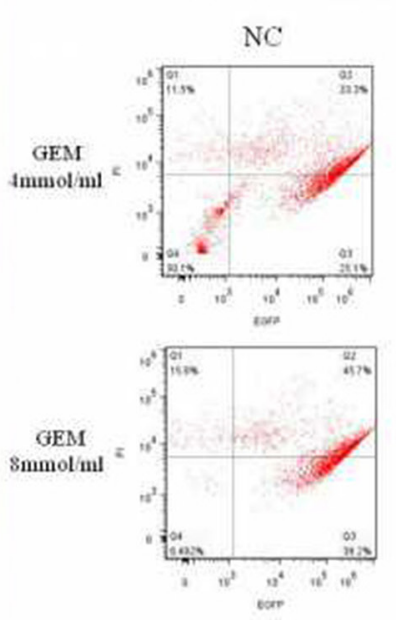

Panc-1

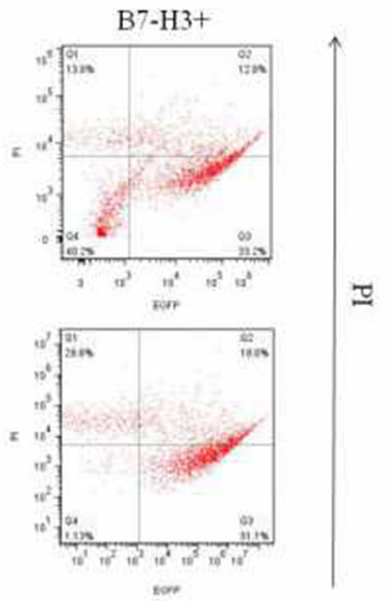

B.

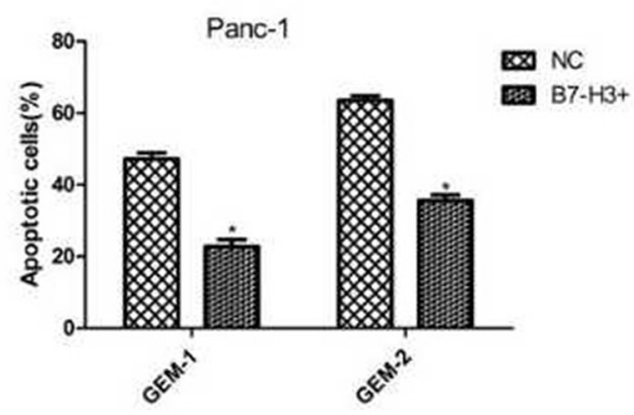

Figure 9: Upregulation of B7-H3 slacked gemcitabine-induced apoptosis in Panc-1 cells. (A) Flow cytometry diagram at $72 \mathrm{~h}$ detected by FITC Annexin V/PI assay. (B) The percentage of PI-stained cells in Panc-1/NC and Panc-1/B7-H3+ cells. The results showed that the percentage of PI-stained cells in Panc-1/B7-H3+cells was less than the percentage in Panc-1/NC cells (Figure 8A and 8B) $(\mathrm{P}<0.05)$. 


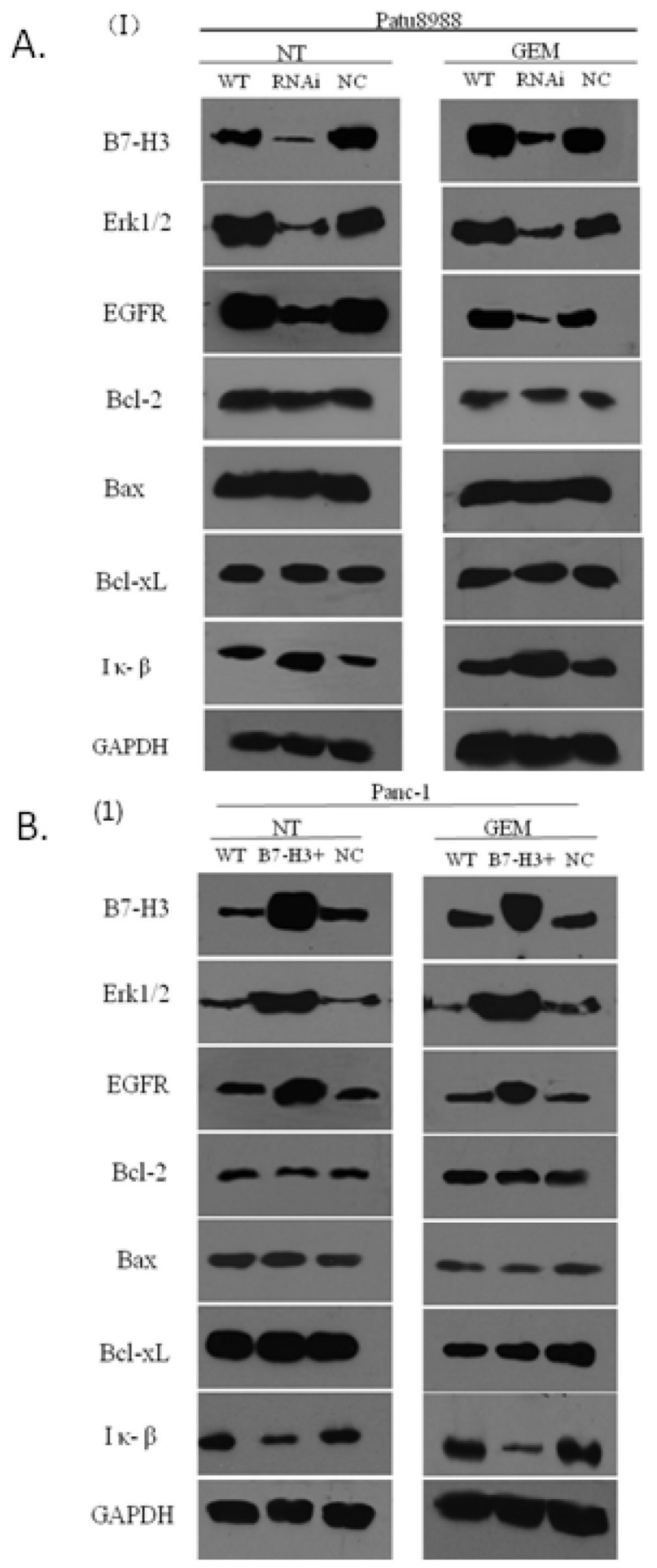

(II)
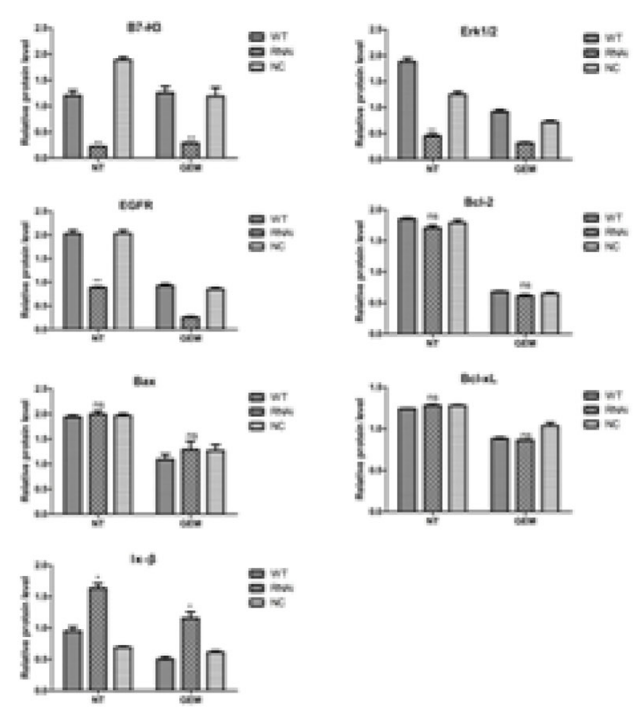

(2)
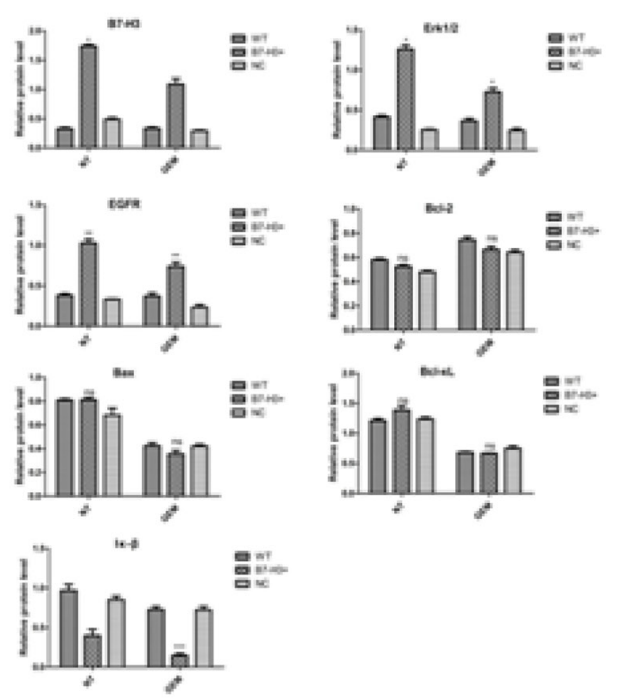

Figure 10: B7-H3 proteins of different cell lines demonstrated by Western blot analysis. (A) Expression levels of Bcl-2, Bax, and Bcl-xL proteins had no obvious difference in Patu8988/WT, Patu8988/NC, and Patu8988/B7-H3- cell lines, regardless of gemcitabine treatment $(\mathrm{P}>0.05)$. The expression levels of EGFR and ERK1/2 proteins significantly decreased $(\mathrm{P}<0.05)$, and the expression level of I $\kappa$ B protein significantly increased $(\mathrm{P}<0.05)$. (B) Expression levels of Bcl-2, Bax, and $\mathrm{Bcl}-\mathrm{xL}$ proteins had no obvious difference in Panc-1/ WT, Panc-1/NC, and Panc-1/B7-H3+ cell lines, regardless of gemcitabine treatment $(\mathrm{P}>0.05)$. The expression levels of EGFR and ERK1/2 proteins significantly increased $(\mathrm{P}<0.05)$, and the expression level of I $\mathrm{kB}$ protein significantly decreased $(\mathrm{P}<0.05)$ (NT, No gemcitabine; GEM, gemcitabine, $8 \mathrm{mmol} / \mathrm{mL}, 48 \mathrm{~h})$. 
cancer (NSCLC), and an elevated level of circulating B7H3 suggested a poor clinical outcome for NSCLC. These results suggested that $\mathrm{B} 7-\mathrm{H} 3$ had a critical role in tumor progression. Furthermore, 42 patients with pancreatic carcinoma were followed, and the survival analysis showed that the patients in the low-B7-H3 expression group was likely to have a longer overall survival compared with those in the high-B7-H3 expression group $(P<0.05)$.

B7-H3, identified in 2001, is a type I transmembrane protein that shares $20 \%-27 \%$ amino acid identity with other B7 family members [18]. Human B7-H3 possesses an isoform, the so-called 4Ig B7-H3 that contains a nearly exact tandem duplication of the $\operatorname{IgV}-\operatorname{IgC}$ domain [19]. Previous studies, through the analysis of the amino acid sequence of B7-H3, found that the intracellular segment consisted of 45 amino acids (aa271-316) and higherpotential serine phosphorylation sites, besides two casein kinase II phosphorylation sites. B7-H3 antibody 4H7 was used to stimulate B7-H3, confirming that B7-H3 could be phosphorylated. Therefore, it was speculated that B7$\mathrm{H} 3$ could influence the biological function of pancreatic cancer cells by transmitting signals in the cells.

The occurrence and development of tumors have a close relationship with apoptosis disorders [20]. Zhang et al [13] found that the overexpression of B7-H3 induced resistance to apoptosis in colorectal cancer cell lines by upregulating the JAK2-STAT3 signaling pathway. Zhao et al [7] demonstrated that silencing of B7-H3, through the lentivirus-mediated delivery of stable shRNA, was observed to increase the sensitivity of the human pancreatic carcinoma cell line Patu8988 to gemcitabine as a result of enhanced drug-induced apoptosis. The present study found that B7-H3 activated by $4 \mathrm{H} 7$ could reduce gemcitabine-induced apoptosis in Patu8988 cells. However, the mechanism is not clear.

Targeted therapies have been increasingly evaluated in patients with metastatic pancreatic cancer. Nearly $60 \%$ of pancreatic cancers demonstrate overexpression of EGFR [21], and therefore EGFR constitutes a promising therapeutic target. More recently, a multicenter trial evaluated the efficacy of cetuximab, an anti-EGFR monoclonal antibody, in combination with gemcitabine and failed to identify improved outcomes [22-24]. Lee et al [25] demonstrated that EGFR-mediated signaling in K-ras mutant pancreatic cancer cells phosphorylated ERK in a Ras-independent fashion, bypassing $G$ proteins and Ras signaling. However, the correlation between B7$\mathrm{H} 3$ and EGFR was not reported. The present study found that $\mathrm{B} 7-\mathrm{H} 3$ activated by $4 \mathrm{H} 7$ could induce variations in p-ERK1/2, EGFR, and IкB protein levels in Patu8988 cells. The expression of p-ERK1/2 and EGFR was upregulated in a dose-dependent manner, whereas the expression of $\mathrm{I} \kappa \mathrm{B}$ was downregulated. NF- $\kappa \mathrm{B}$ is the most important transcription factor in inflammatory pathways that play major roles in tumorigenesis and thus can be considered targets for cancer prevention and therapy [26].
$\mathrm{NF}-\kappa \mathrm{B}$, a key mediator of inflammatory response, plays a significant role in carcinogenesis and is now emerging as a link between inflammation and cancer. Inhibition of constitutive NF- $\kappa \mathrm{B}$, activity by a phosphorylation-

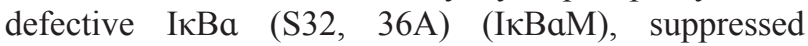
pancreatic tumorigenesis in an orthotopic nude mouse model [27]. Tan et al [28] showed that metformin might inhibit pancreatic tumorigenesis by modulating multiple molecular targets in inflammatory pathways, including NF- $\kappa$ B/STAT3 inflammatory signaling. The present results indicated that B7-H3 might be associated with pancreatic cancer resistance to gemcitabine chemotherapy.

Based on the aforementioned results, pancreatic cancer cells with B7-H3 overexpression were knocked down in subsequent studies to identify possible proteins that mediated B7-H3 signaling resulting in chemotherapy resistance. It was found by RT-PCR that the expression of EGFR was associated with the expression of B7-H3 in the pancreatic cancer cell resistant to gemcitabine, and the upregulation of B7-H3 slacked gemcitabine-induced apoptosis in Panc-1 cells. The members of Bcl-2 protein family appear to be important factors in cell apoptosis [29]. Moreover, I $\kappa \mathrm{B}$ was deemed to be related to cell apoptosis [30]. Therefore, Bcl-2, Bax, Bcl-xL, EGFR, Erk1/2, and $\mathrm{I} \kappa \mathrm{B}$ proteins were detected by Western blot and semiquantitative analysis. When B7-H3 was upregulated, the expression levels of EGFR and ERK1/2 proteins significantly increased $(P<0.05)$, and the expression level of IкB significantly decreased $(P<0.05)$, especially in the gemcitabine-treated group. It has previously been shown that $\mathrm{B} 7-\mathrm{H} 3$ regulates the expression of Bcl-2, Bcl-xL, and Bax via the JAK2/STAT3 signaling pathway to increase the anti-apoptotic ability of cancer cells [13]. Also, Liu et al [31] showed that $\mathrm{B} 7-\mathrm{H} 3$ promoted cell migration and invasion through the JAK2/STAT3/MMP9 signaling pathway in colorectal cancer. However, the expression of Bcl-2, Bcl-xL, and Bax had no obvious difference, irrespective of B7-H3 upregulation or downregulation, in the present study. These results indicated that B7-H3 could accommodate the variations in EGFR to mediate pancreatic cancer cell resistance to gemcitabine-induced apoptosis.

In conclusion, the present study demonstrated that B7-H3 could deliver signals to pancreatic cancer cells to combat the apoptosis induced by gemcitabine. It also showed the molecular mechanisms underlying the aforementioned effect. These findings indicated a novel role of $\mathrm{B} 7-\mathrm{H} 3$ in the regulation of chemotherapy resistance of pancreatic cancer cells. B7-H3 may serve as a potential therapeutic target in the progression of pancreatic cancer.

\section{MATERIALS AND METHODS}

\section{Reagents}

B7-H3 (D9M2L) XP rabbit monoclonal antibody (mAb), Bcl-2(50E3) rabbit mAb, Bcl-xL (54H6) rabbit mAb, 
Bax (D2E11) rabbit mAb, EGF receptor (C74B9) (D9M2L) rabbit $\mathrm{mAb}$, I $\mathrm{B}$-alpha (44D4) rabbit $\mathrm{mAb}$, ERK rabbit $\mathrm{mAb}, \mathrm{p}$-ERK rabbit $\mathrm{mAb}$ and glyceraldehyde 3-phosphate dehydrogenase (GAPDH) rabbit $\mathrm{mAb}$ were purchased from Cell Signaling Technology (USA). 4H7(Jiangsu Key Laboratory of Clinical Immunology, Soochow University, Suzhou). The horseradish peroxidase-conjugated secondary anti-rabbit antibodies were purchased from Bio-Rad (CA, USA). Gemcitabine was purchased from Lilly France, Inc. (Neuilly, France). A Phosphoprotein Purification Kit was purchased from Qiagen Sample and Assay Technologies (Germany). Dulbecco's modified Eagle's Medium (DMEM) was purchased from Sigma-Aldrich (MO, USA). Fetal bovine serum (FBS) was supplied by Sijiqing Biological Manufacturer Co., Ltd (Hangzhou, China). The Annexin Vfluorescein isothiocyanate (FITC) Apoptosis Detection Kit was purchased from Miltenyi Biotec (Germany).

\section{Cells and cell culture}

The pancreatic cancer cell lines Panc-1 and Patu8988 were purchased from the Chinese Academy of Science Cell Bank. Panc-1 cells were cultured in DMEM, and Patu8988 cells were cultured in RPMI-1640 medium. All media were supplemented with $10 \% \mathrm{FBS}$ and $1 \%$ penicillinstreptomycin (Gibco-BRL) at $37^{\circ} \mathrm{C}$ in $5 \% \mathrm{CO}_{2}$ atmosphere.

\section{Clinical specimens from patients and survival analysis}

Clinical surgical specimens were obtained from 42 patients with pancreatic carcinoma who underwent surgery between October 2010and December 2012 at the First Affiliated Hospital of Soochow University. The diagnosis of pancreatic carcinoma was confirmed by histopathology. The patients did not receive preoperative adjuvant treatment before surgery. Tumor tissues were dissected, and paired adjacent normal pancreatic tissues were obtained from the same patients. The tissue specimens were immediately fixed in $10 \%$ buffered formalin for immunohistochemical estimation of expression of B7-H3 and then stored at $-80^{\circ} \mathrm{C}$ until further use. Reverse transcription-polymerase chain reaction (RT-PCR) was performed to detect the expression of B7-H3 from 42 pancreatic carcinoma specimens. The clinical follow-up period of patients ranged from 1 to 60 months. Clinical data were applied to survival analysis. The overall survival time was defined as the interval from the date of diagnosis to pancreatic carcinoma-related death. This clinical study was approved by the ethics committee of The First Affiliated Hospital of Soochow University.

\section{Phosphoprotein purification from cultured Patu8988 cells}

Patu8988 cells were preincubated with or without 4H7 for $30 \mathrm{~min}$. Isolation of phosphoproteins from cellular extracts was carried out using the Phosphoprotein Purification Kit according to the manufacturer's protocol. In short, a cell pellet corresponding to $10^{7}$ cells was resuspended in $5 \mathrm{~mL}$ of lysis buffer containing protease inhibitors and Benzonase Nuclease. The mixture was incubated for $30 \mathrm{~min}$ at $4^{\circ} \mathrm{C}$ and vortexed briefly every $10 \mathrm{~min}$. The supernatant was harvested, and the protein concentration was determined. The protein concentration was measured in all eluted fractions to determine the most concentrated fraction. Then, Western blot was implemented with anti-human B7-H3 antibody to detect the phosphorylated $\mathrm{B} 7-\mathrm{H} 3$ protein.

\section{Evaluation of cell apoptosis by propidium iodide-annexin $\mathrm{V}$ staining}

Cell apoptosis was evaluated by propidium iodide (PI)-AnnexinV staining to investigate the relation between the expression of B7-H3 and Patu8988 cells treated with gemcitabine. This study used B7-H3 antibody 4H7. Briefly, $1 \times 10^{5} /$ well Patu8988 cells were paved into six-well plates and cultured overnight. Then, the cells were assorted into five groups: control group, $4 \mathrm{mmol} / \mathrm{mL}$ gemcitabine group, $4 \mathrm{mmol} / \mathrm{mL}$ gemcitabine $+2.5 \mu \mathrm{g} / \mathrm{mL} 4 \mathrm{H} 7$ group, $8 \mathrm{mmol} /$ $\mathrm{mL}$ gemcitabine group, and $8 \mathrm{mmol} / \mathrm{mL}$ gemcitabine +2.5 $\mu \mathrm{g} / \mathrm{mL} 4 \mathrm{H} 7$ group. The treatment lasted for $48 \mathrm{~h}$. Subsequent to harvesting, the cells were resuspended in $100 \mu \mathrm{L}$ of $1 \times$ binding buffer. Next, $10 \mu \mathrm{L}$ of Annexin V-FITC was added, and the mixture was incubated in the dark for $15 \mathrm{~min}$ at room temperature. After washing and centrifuging cells, the cell pellet was resuspended in $500 \mu \mathrm{L}$ of $1 \times$ binding buffer. Finally, $5 \mu \mathrm{L}$ of the PI solution was added immediately prior to analysis by FACSCalibur flow cytometry (FCM) and FlowJo7.6 software. This experiment was repeated three times. After Panc-1 cells were transfected with B7$\mathrm{H} 3$ lentivirus and $\mathrm{NC}$ lentivirus, the aforementioned method was used to detect the cell apoptosis status. B7-H3+/Panc1 and NC/Panc-1 cells were separately treated with 4 and $8 \mathrm{mmol} / \mathrm{mL}$ gemcitabine for 48 and $72 \mathrm{~h}$, respectively. Then, PI-Annexin V Staining Apoptosis Detection Kit I manual (Invitrogen Life Technologies, CA, USA) was implemented. However, it was that the green fluorescent protein (GFP) expression was capable of interfering with the FITC analysis assessed by flow cytometry, as both expressed a similar green fluorescence. Therefore, PI reagent was used only to detect apoptosis. This experiment was repeated three times.

\section{Lentivirus transfection of human pancreatic cancer cell lines Patu8988 and Panc-1}

shRNA of the human B7-H3 (5'-CTCTGCC TTCTCACCTCTTTG-3') and overexpressing hB7-H3 of lentivirus gene transfer vectors encoding the GFP sequence were constructed by Shanghai Genechem Co. (Shanghai, China). 
The control lentivirus gene transfer vectors for the downregulation and upregulation of $\mathrm{hB} 7-\mathrm{H} 3$, respectively, were the nontargeted control mock lentivirus ( $\left.\mathrm{LV}-\mathrm{NC}^{-}\right)$and $\mathrm{LV}_{-} \mathrm{NC}^{+}$. Patu8988 cells were transfected with shRNA/ B7-H3 and LV-NC-/B7-H3 lentivirus, and Panc-1 cells were transfected with $\mathrm{LV}-\mathrm{B} 7-\mathrm{H}^{+}$and $\mathrm{LV}-\mathrm{NC}^{+} / \mathrm{B} 7-\mathrm{H} 3$ lentivirus, according to the manufacturer's instructions. After transfection, FCM, RT-PCR, and Western blot analysis were performed to confirm the downregulation and upregulation of $\mathrm{B} 7-\mathrm{H} 3$ mRNA and protein in Patu8988 and Panc-1 cell lines, respectively

\section{Quantitative real-time RT-PCR}

The total RNA was isolated from cell lines using TRIzol, following the manufacturer's instructions and quantified using a NanoDrop 2000 spectrophotometer (Thermo Scientific, MA, USA). The total RNA was treated with RNase-free DNase to remove residual genomic DNA. The first-strand cDNA was synthesized from $1.0 \mu \mathrm{g}$ RNA using an oligo-dT primer and avian myeloblastosis virus reverse transcriptase. The real-time mRNA expression analysis of target genes (B7-H3 and EGFR) and housekeeping gene (GAPDH) for control was performed using the SYBR Green Real-time PCR Master Mix and real-time PCR amplification equipment. The primer sequences were as follows: sense sequence ( $5^{\prime}$ to $3^{\prime}$ ) CTCTGCCTTCTCACCTCTTTG and antisense sequence ( $5^{\prime}$ to 3') CCTTGAGGGAGGAACTTTATC for B7-H3; sense sequence (5' to 3') CCCACTCATGCTCTACAACCC and antisense sequence (5'to 3') TCGCACTTCTTACACTTGCGG for EGFR; and sense sequence (5'to 3') TGACTTCAACAGCGACACCCA and antisense sequence (5'to 3') CACCCTGTTGCTGTAGCCAAA for GAPDH. The PCR conditions consisted of one cycle at $95^{\circ} \mathrm{C}$ for 15 $\mathrm{s}$, followed by 45 cycles at $95^{\circ} \mathrm{C}$ for $5 \mathrm{~s}$ and at $60^{\circ} \mathrm{C}$ for 30 $\mathrm{s}$. The relative quantification was provided by the $\mathrm{Ct}$ values using the $2^{-\Delta \Delta \mathrm{Ct}}$ method, determining the reactions for target genes and an internal control gene in all samples. Assays were triplicated, and the average expressions levels were determined.

\section{Immunohistochemistry staining analyses}

Clinical specimens were used for immunohistochemical staining analyses. Paraffinembedded tissues were cut into $4-\mu \mathrm{m}$ sections and incubated with the rabbit anti-human $\mathrm{B} 7-\mathrm{H} 3$ polyclonal antibody (1:50 dilution) overnight at $4^{\circ} \mathrm{C}$. SP-9000 Histostain-Plus kits (ZSGB-BIO, Beijing, China) were used according to the manufacturer's instructions. The brown staining in the cytoplasm was read as positive reactivity for B7-H3. Scoring was measured according to the cell cytoplasm staining pattern: 0 , no cytoplasmic staining;1, weak cytoplasmic staining; 2, moderate cytoplasmic staining; and 3, strong cytoplasmic staining.

\section{Flow cytometry}

After the prescribed treatments, the cells were trypsinized, collected, and washed three times with phosphate-buffered saline (PBS). They were then fixed in $70 \%$ ice-cold ethanol for $2 \mathrm{~h}$. They were resuspended in PBS at a concentration of $10^{6}$ cells $/ \mathrm{mL}$ and then incubated with PI for $2 \mathrm{~h}$ at room temperature in the dark. Finally, the cells were analyzed by FACScan (Becton-Dickinson, CA, USA) using the FlowJo 7.6 software.

\section{Western blot analysis}

The harvested cells were washed with PBS and lysed with cell lysis buffer on ice. The protein concentrations were tested using the Bicinchoninic Acid Protein Assay Kit. Equal amounts of protein samples were prepared and fractionated by electrophoresis using sodium dodecyl sulfate-polyvinylidene difluoride membrane. The membranes were blocked and incubated with primary antibodies at $4^{\circ} \mathrm{C}$ overnight. Then, they were washed three times with Tris-buffered saline and Tween 20 and incubated with a second antibody at room temperature for $2 \mathrm{~h}$. Following further washing, the protein bands were subsequently detected by an enhanced chemiluminescence assay, with the exposure time according to the brightness of the band. The intensities of the bands were calculated by semiquantitative analysis using the Image $J$ software. Each experiment was repeated three times.

\section{Statistical analyses}

Data are presented as mean ( \pm standard deviation). Differences in mean values between groups were analyzed by one-way analysis of variance, and Student $t$ test was used for comparing two groups. At least three independent experiments were performed for all the studies. Differences were considered to be statistically significant when $P$ values were less than 0.05 . The data were analyzed using GraphPad Prism 6 (GraphPad Software Inc., CA, USA).
Abbreviations
B7-H3: B7 Homolog 3
DC: dendritic cell
FITC: fluorescein isothiocyanate
MOI: multiplicity of infection
EGFP: enhanced green fluorescent protein
FCM: flow cytometry
RT-PCR: real-time polymerase chain reaction
IFN- $\gamma$ : Interferon- $\gamma$
EGFR: epidermal growth factor receptor
Bcl-2: B-cell lymphoma-2 


\section{Authors contributions}

Dr. Xin Zhao and Dr. Gang Chen proposed the study and are the guarantors. Dr. Dongbao Li wrote the first draft. Dongbao Li, Jun Wang, and Jian Zhou contributed equally to this article. All authors contributed to the design and interpretation of the study and to further drafts.

\section{ACKNOWLEDGMENTS}

This study was supported by grants from the Postdoctoral Science Foundation Grant of China (no.2016M591913). Jiangsu Provincial Medical Youth Talent (QNRC2016732). National Science Foundation of China (NSFC, no.81302146). Provincial Natural Science Foundation of Jiangsu Province (no.BK20161225). Scientific Research Program of Jiangsu Provincial Commission of Health and Family Planning (H201620). Science and Technology Program of Suzhou City, China (SYS201539). Jiangsu Provincial "Six Peaks Talent" Program (2016-WSW-043).

\section{CONFLICTS OF INTEREST}

The authors declare no conflicts of interest regarding the content of this article.

\section{REFERENCES}

1. Van Rijssen LB, Rombouts SJ, Walma MS, Vogel JA, Tol JA, Molenaar IQ, van Eijck $\mathrm{CH}$, Verheij J, van de Vijver MJ, Busch OR, Besselink MG. Recent advances in pancreatic cancer surgery of relevance to the practicing pathologist. Surg Pathol Clin. 2016; 9:539-545.

2. Siegel RL, Miller KD, Jemal A. Cancer statistics, 2015. CA Cancer J Clin. 2015; 65:5-29.

3. Szakács G, Paterson JK, Ludwig JA, Booth-Genthe C, Gottesman MM. Targeting multidrug resistance in cancer. Nat Rev Drug Discov. 2006; 5:219-34.

4. Xu X, Wei Q, Wang K, Ling Q, Xie H, Zhou L, Zheng S. Anticancer effects of Huaier are associated with down-regulation of P53. Asian Pac J Cancer Prev. 2011; 12:2251-4.

5. de Sousa Cavalcante L, Monteiro G. Gemcitabine: metabolism and molecular mechanisms of action, sensitivity and chemoresistance in pancreatic cancer. Eur J Pharmacol. 2014; 741:8-16.

6. Zhang Z, Duan Q, Zhao H, Liu T, Wu H, Shen Q, Wang C, Yin T. Gemcitabine treatment promotes pancreatic cancer stemness through the Nox/ROS/NF- $\mathrm{BB} / \mathrm{STAT} 3$ signaling cascade. Cancer Lett. 2016; 382:53-63.

7. Zhao X, Zhang GB, Gan WJ, Xiong F, Li Z, Zhao H, Zhu DM, Zhang B, Zhang XG, Li DC. Silencing of B7-H3 increases gemcitabine sensitivity by promoting apoptosis in pancreatic carcinoma. Oncol Lett. 2013; 5:805-812.
8. Steinberger P, Majdic O, Derdak SV, Pfistershammer K, Kirchberger S, Klauser C, Zlabinger G, Pickl WF, Stöckl J, Knapp W. Molecular characterization of human 4Ig-B7-H3, a member of the B7 family with four Ig-like domains. J Immunol. 2004; 172:2352-9.

9. Zhou YH, Chen YJ, Ma ZY, Xu L, Wang Q, Zhang GB, Xie F, Ge Y, Wang XF, Zhang XG. 4IgB7-H3 is the major isoform expressed on immunocytes as well as malignant cells. Tissue Antigens. 2007; 70:96-104.

10. Zhang GB, Zhou H, Chen YJ, Ge Y, Xie F, Shi Q, Ma HB, Fei M, Zhang XG. Characterization and application of two novel monoclonal antibodies against 2IgB7-H3: expression analysis of $2 \operatorname{IgB} 7-\mathrm{H} 3$ on dendritic cells and tumor cells. Tissue Antigens. 2005; 66:83-92.

11. Yamato I, Sho M, Nomi T, Akahori T, Shimada K, Hotta K, Kanehiro H, Konishi N, Yagita H, Nakajima Y. Clinical importance of B7-H3 expression in human pancreatic cancer. Br J Cancer. 2009; 101:1709-16.

12. Zhang W, Wang J, Wang Y, Dong F, Zhu M, Wan W, Li $\mathrm{H}, \mathrm{Wu}$ F, Yan X, KeX. B7-H3 silencing by RNAi inhibits tumor progression and enhances chemosensitivity in U937 cells. Onco Targets Ther. 2015; 8:1721-33.

13. Zhang T, Jiang B, Zou ST, Liu F, Hua D. Overexpression of B7-H3 augments anti-apoptosis of colorectal cancer cells by Jak2-STAT3. World J Gastroenterol. 2015; 21:1804-13.

14. Ingebrigtsen VA, Boye K, Tekle C, Nesland JM, Flatmark K, Fodstad O. B7-H3 expression in colorectal cancer: nuclear localization strongly predicts poor outcome in colon cancer. Int J Cancer. 2012; 131:2528-36.

15. Wu CP, Jiang JT, Tan M, Zhu YB, Ji M, Xu KF, Zhao JM, Zhang GB, Zhang XG. Relationship between co-stimulatory molecule B7-H3 expression and gastric carcinoma histology and prognosis. World J Gastroenterol. 2006; 12:457-9.

16. Zhao X, Li DC, Zhu XG, Gan WJ, Li Z, Xiong F, Zhang ZX, Zhang GB, Zhang XG, Zhao H. B7-H3 overexpression in pancreatic cancer promotes tumor progression. Int $\mathrm{J}$ Mol Med. 2013; 31:283-91.

17. Zhang G, Xu Y, Lu X, Huang H, Zhou Y, Lu B, Zhang X. Diagnosis value of serum B7-H3 expression in non-small cell lung cancer. Lung Cancer. 2009; 66:245-9.

18. Chapoval AI, Ni J, Lau JS, Wilcox RA, Flies DB, Liu D, Dong H, Sica GL, Zhu G, Tamada K, Chen L. B7-H3: a costimulatory molecule for $\mathrm{T}$ cell activation and IFNgamma production. Nat Immunol. 2001; 2:269-74.

19. Steinberger P, Majdic O, Derdak SV, Pfistershammer K, Kirchberger S, Klauser C, Zlabinger G, Pickl WF, Stöckl J, Knapp W. Molecular characterization of human 4Ig-B7-H3, a member of the B7 family with four Ig- likedomains. J Immunol. 2004; 172:2352-9.

20. Han B, Park D, Li R, Xie M, Owonikoko TK, Zhang G, Sica GL, Ding C, Zhou J, Magis AT, Chen ZG, Shin DM, Ramalingam SS, et al. Small-Molecule Bcl2 BH4 Antagonist for Lung Cancer Therapy. Cancer Cell. 2015; $27: 852-63$ 
21. Korc M, Friess H, Yamanaka Y, Kobrin MS, Buchler M, Beger HG. Chronic pancreatitis is associated with increased concentrations of epidermal growth factor receptor, transforming growth factor alpha, and phospholipase C gamma. Gut. 1994; 35:1468-73.

22. Burris HA 3rd, Moore MJ, Andersen J, Green MR, Rothenberg ML, Modiano MR, Cripps MC, Portenoy RK, Storniolo AM, Tarassoff P, Nelson R, Dorr FA, Stephens $\mathrm{CD}$, et al. Improvements in survival and clinical benefit with gemcitabine as first-line therapy for patients with advanced pancreas cancer: a randomized trial. J Clin Oncol. 1997; 15:2403-13.

23. Moore MJ, Goldstein D, Hamm J, Figer A, Hecht JR, Gallinger S, Au HJ, Murawa P, Walde D, Wolff RA, Campos D, Lim R, Ding K, et al. Erlotinib plus gemcitabine compared with gemcitabine alone in patients with advanced pancreatic cancer: a phase III trial of the National cancer Institute of Canada Clinical Trials Group. J Clin Oncol. 2007; 25:1960-6.

24. Philip PA, Benedetti J, Corless CL, Wong R, O'Reilly EM, Flynn PJ, Rowland KM, Atkins JN, Mirtsching BC, Rivkin SE, Khorana AA, Goldman B, Fenoglio-Preiser CM, et al. Phase III study comparing gemcitabine plus cetuximab versus gemcitabine in patients with advanced pancreatic adenocarcinoma: Southwest Oncology Group-directed intergroup trialS0205. J Clin Oncol. 2010; 28:3605-10.

25. Lee S, Heinrich EL, Lu J, Lee W, Choi AH, Luu C, Chung V, Fakih M, Kim J. Epidermal growth factor receptor signaling to the mitogen activated protein kinase pathway bypasses ras in pancreatic cancer cells. Pancreas. 2016; 45:286-92.

26. Lin WW, Karin M. A cytokine-mediated link between innate immunity, inflammation, and cancer. J Clin Invest. 2007; 117:1175-83.

27. Fujioka S, Sclabas GM, Schmidt C, Niu J, Frederick WA, Dong QG, Abbruzzese JL, Evans DB, Baker C, Chiao PJ. Inhibition of constitutive NF-kappa B activity by I kappa B alpha M suppresses tumorigenesis. Oncogene. 2003; 22:1365-70.

28. Tan XL, Bhattacharyya KK, Dutta SK, Bamlet WR, Rabe KG, Wang E, Smyrk TC, Oberg AL, Petersen GM, Mukhopadhyay D. Metformin suppresses pancreatic tumor growth with inhibition of NF- $\kappa$ B/STAT3 inflammatorysignaling. Pancreas. 2015; 44:636-47.

29. Zhou F, Yang Y, Xing D. Bcl-2 and Bcl-xL play important roles in the crosstalk between autophagy and apoptosis. FEBS J. 2011; 278:403-13.

30. de Nigris F, Gallo L, Sica V, Napoli C. Glycoxidation of low-density lipoprotein promotes multiple apoptotic pathways and NFkappaB activation in human coronary cells. Basic Res Cardiol. 2006; 101:101-8.

31. Liu F, Zhang T, Zou S, Jiang B, Hua D. B7-H3 promotes cell migration and invasion through the Jak2/Stat3/MMP9 signaling pathway incolorectal cancer. Mol Med Rep. 2015; 12:5455-60. 